\title{
Upaya Mitigasi Bencana Banjir di Kabupaten Pidie Jaya Provinsi Aceh untuk Mendukung Keamanan Nasional
}

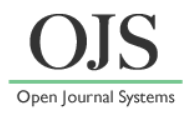

\author{
Islamia Kharimah $^{1 *}$, Dewi Wahyuni ${ }^{1}$, Aprilyanto ${ }^{1}$, I Dewa Ketut Kerta Widana ${ }^{2}$ \\ ${ }^{1}$ Mahasiswa Prodi Manajemen Bencana, Fakultas Keamanan Nasional, Universitas Pertahanan \\ ${ }^{2}$ Sesprodi Manajemen Bencana, Fakultas Keamanan Nasional, Universitas Pertahanan \\ *Email: islamiakharimah31@gmail.com
}

DOI: https://doi.org/10.33369/pendipa.6.1.57-63

\begin{abstract}
[Flood Disaster Mitigation Efforts in Pidie Jaya District, Aceh Province to Support National Security]. This study was conducted to analyze flood disaster mitigation efforts in Pidie Jaya District to support national security. This research used a qualitative method and descriptive analysis. The data used in this research were primary and secondary data. Primary data was obtained through interviews conducted online using the zoom meeting application on March 22-25, 2021 involving several agencies in Pidie Jaya District such as, Badan Penanggulangan Bencana Daerah (BPBD), Dinas Lingkungan Hidup, Badan Perencanaan Pembangunan Daerah (Bappeda), dan Dinas Pekerjaan Umum. Secondary data is obtained through documents held by agencies related to flood disasters. The results of this research indicate that the Pidie Jaya District Government has made mitigation efforts for flood disasters such as coordinating with related sectors, identify disaster-prone areas, conduct socialization and provide education on disaster management, as well as strengthen structures in the cliff areas of Krueng Meureudu, Krueng Putu, and Krueng Jeulanga. However, these efforts did not run optimally because one of the factors causing the flooding had not been eliminated. The solution that can be offered by the author is that it is necessary to make contingency plans and documents for disaster-prone areas, an early warning system for flood disasters, as well as legal strengthening for illegal logging actors in the upstream area of the river which is one of the factors causing flooding.
\end{abstract}

Keywords: Flood; Mitigation; Pidie Jaya.

\begin{abstract}
ABSTRAK
Penelitian ini bertujuan untuk menganalisis upaya mitigasi dalam penanganan bencana banjir di Kabupaten Pidie Jaya untuk mendukung keamanan nasional. Penelitian ini menggunakan metode kualitatif dengan menggunakan analisis deskriptif. Data yang digunakan pada penelitian ini adalah data primer dan data sekunder. Data primer didapatkan melalui wawancara yang diperoleh secara online menggunakan aplikasi zoom meeting pada tanggal 22-25 Maret 2021 dengan melibatkan beberapa instansi di Kabupaten Pidie Jaya yaitu Badan Penanggulangan Bencana Daerah (BPBD), Dinas Lingkungan Hidup, Badan Perencanaan Pembangunan Daerah (Bappeda), dan Dinas Pekerjaan Umum. Data sekunder didapatkan melalui dokumen yang dimiliki oleh instansi terkait dengan bencana banjir. Hasil penelitian ini diketahui bahwa Pemerintah Kabupaten Pidie Jaya telah melakukan upaya-upaya mitigasi untuk bencana banjir seperti, melakukan koordinasi dengan lintas sektor terkait, melakukan identifikasi kawasan rawan bencana, melakukan sosialisasi dan memberikan edukasi tentang penanggulangan bencana, serta memperkuat struktural di kawasan tebing Krueng Meureudu, Krueng Putu, dan Krueng Jeulanga. Namun, upaya tersebut tidak berjalan maksimal karena salah satu faktor penyebab banjir masih belum dihilangkan. Solusi yang dapat ditawarkan oleh penulis adalah perlu dilakukan pembuatan rencana kontinjensi dan dokumen kawasan rawan bencana, perlu adanya early warning system untuk bencana banjir, serta penguatan hukum bagi pelaku pembalakan liar di kawasan hulu sungai yang menjadi salah satu faktor penyebab banjir.
\end{abstract}

https://ejournal.unib.ac.id/index.php/pendipa 
Kata kunci: Banjir; Mitigasi; Pidie Jaya.

\section{PENDAHULUAN}

Bencana yang paling sering terjadi di dunia adalah bencana banjir (Doocy et al., 2013) termasuk di Kabupaten Pidie Jaya yang dapat menimbulkan kerusakan, mengganggu kenyamanan manusia, bahkan mengganggu psikologis orang yang terdampak (Nquot \& Kulatunga, 2014). Berdasarkan data selama tahun 2017-2021, setiap tahun terjadi banjir di beberapa wilayah dan menurut hasil kajian risiko bencana Provinsi Aceh, Kabupaten Pidie Jaya memiliki potensi luas bahaya banjir yang tinggi. Banjir adalah tergenangnya daerah atau lahan karena peningkatan volume air (Badan Penanggulangan Bencana Aceh, 2016; BPBD Kabupaten Pidie Jaya, 2021).

Beberapa hasil penelitian terkait banjir menyatakan sepertiga dari bencana alam di dunia adalah bencana banjir. Satu dari sepuluh korban jiwa akibat bencana alam adalah korban banjir. Banjir bertanggung jawab atas sepertiga dari keseluruhan kerugian ekonomi (250 milyar USD di seluruh dunia selama lima belas tahun terakhir). Di negara berkembang sebanyak 9597\% kematian akibat bencana alam disebabkan oleh banjir. Dampak yang ditimbulkan oleh banjir berbeda tergantung kondisi geografis, pertanian, dan ekonomi (Tariq et al., 2020)

Proses yang menyebabkan terjadinya banjir cukup kompleks dan banjir dapat terjadi akibat kombinasi dari berbagai proses yang ada di siklus hidrologis (Becker, 2018). Banjir sangat berkaitan dengan faktor meteorologi, topografi, penggunaan lahan, dan tipe tanah (Agbola et al., 2012; Youssef et al., 2016). Tingginya curah hujan menyebabkan sungai yang ada tidak mampu menampung air dan keadaan ini diperparah dengan terjadinya penyumbatan aliran sungai. Menurut Dinas Lingkungan Hidup Kabupaten Pidie Jaya, tindakan penggundulan hutan ilegal masih terjadi dan di sepanjang sungai masih ditemukan rumah warga yang dapat meningkatkan risiko terjadinya banjir (Dinas Lingkungan Hidup Kabupaten Pidie Jaya, 2021).

Untuk mengurangi risiko bencana banjir diperlukan suatu upaya mitigasi sebagaimana yang telah tertuang di dalam Undang-Undang RI Nomor 24 Tahun 2007 dan Qanun Aceh Nomor 5 Tahun 2010 tentang Penanggulangan Bencana.
Mitigasi bencana banjir dapat dilakukan secara struktural maupun non struktural sebagaimana yang dilakukan di Kabupaten Tasikmalaya yang mana untuk mengurangi risiko banjir dilakukan pemeliharaan kondisi hutan, membuat tapak bangunan kurang lebih $15 \mathrm{~cm}$ lebih tinggi dari lorong, lorong tersebut berperan sebagai drainase, membentuk kolam yang memisahkan rumah dari sungai, dan membuat lorong tanpa semen yang berfungsi sebagai drainase (Dewi \& Istiadi, 2016).

Di daerah rawan banjir sangat penting untuk memahami penyebab terjadinya banjir, menilai risiko terjadinya banjir, dan mengadopsi strategi mitigasi berbasis lanskap dapat meningkatkan pengetahuan, kewaspadaan, dan upaya individu untuk melindungi diri dan harta benda dengan upaya manajemen bencana banjir yang tepat (Erena \& Worku, 2018). Beberapa penelitian sebelumnya terkait penyebab banjir dan strategi mitigasi menunjukkan faktor pemicu banjir pada umumnya berkaitan dengan efek meteorologi, hidrologi, dan antropogenik (Agbola et al., 2012) sehingga upaya mitigasi yang dilakukan seharusnya juga mempertimbangkan faktor tersebut.

Terdapat beberapa penelitian mengenai mitigasi bencana banjir, diantaranya adalah penelitian yang dilakukan oleh Prawira dan Pamungkas (2014) bertujuan merencanakan mitigasi untuk bencana banjir rob di Pantai Utara Surabaya (Prawira \& Pamungkas, 2014). Penelitian kedua dilakukan oleh Wibowo et al. (2019) dengan mempertimbangkan sejarah bencana banjir dan kerentanan ekonomi, sosial, lingkungan dan fisik, untuk menetapkan rencana mitigasi bencana non-struktural yang sesuai untuk bagian hilir Daerah Aliran Sungai Comal di Kabupaten Parmarang (Wibowo et al., 2019). Selanjutnya penelitian ketiga dilakukan oleh Afrian (2020) yang bertujuan untuk mengetahui penyebab banjir di Desa Sidodadi dan mengetahui upaya mitigasi bencana banjir yang sesuai di Desa Sidodadi Kota Langsa (Afrian, 2020). Perbedaan dari ketiga penelitian tersebut terletak pada lokasi penelitian, penyebab terjadinya bencana banjir, upaya mitigasi yang direncanakan, serta metode penelitian yang digunakan. Penelitian ini bertujuan untuk 
menganalisis upaya mitigasi dalam penanggulangan bencana banjir di Kabupaten Pidie Jaya untuk mendukung keamanan nasional.

\section{METODE PENELITIAN}

Penelitian ini menggunakan data primer dan data sekunder. Data primer diperoleh melalui wawancara yang dilakukan secara online menggunakan aplikasi zoom meeting pada tanggal 22-25 Maret 2021 dengan melibatkan beberapa instansi di Kabupaten Pidie Jaya yaitu Badan Penanggulangan Bencana Daerah (BPBD), Dinas Lingkungan Hidup, Badan Perencanaan Pembangunan Daerah (Bappeda), dan Dinas Pekerjaan Umum. Data sekunder didapatkan melalui dokumen yang dimiliki oleh instansi terkait dengan bencana banjir. Penelitian ini menggunakan data tahun 2017-2020. Metode kualitatif digunakan pada penelitian ini dengan menggunakan analisis deskriptif. Setelah melakukan wawancara dengan instansi-instansi terkait, tahap selanjutnya adalah menelaah dokumen yang dimiliki instansi terkait dan upaya mitigasi yang dilakukan. Data primer dan sekunder yang telah didapatkan selanjutnya ditelaah hingga membentuk tulisan yang dapat dianalisis.

\section{HASIL DAN PEMBAHASAN}

Penyebab terjadinya banjir di Kabupaten Pidie Jaya yaitu meningkatnya intensitas curah hujan, masih adanya penebangan liar, dan masih banyak penduduk yang bermukim di daerah pinggir sungai. Hal ini juga terjadi di kabupaten lainnya di Provinsi Aceh yaitu Aceh Singkil yang rawan terjadi bencana banjir. Topografi wilayahnya terbagi dalam wilayah daratan dan kepulauan yang masyarakatnya lebih banyak bermukim di daerah pinggir sungai (Ismail et al., 2020). Selain itu, perubahan iklim juga turut berkontribusi menyebabkan terjadinya banjir karena curah hujan meningkat dan kenaikan air laut lebih sering terjadi (Bariweni et al., 2012).

Penyebab banjir yang terjadi di Nigeria dibagi menjadi dua kategori yaitu penyebab alami dan akibat perbuatan manusia. Penyebab alami terdiri atas curah hujan yang tinggi, badai laut dan gelombang tidal, jumlah danau sedikit, dan terjadinya pendangkalan sungai. Perilaku manusia yang dapat memicu terjadinya banjir yaitu kegagalan bendungan, kepadatan penduduk, penggundulan hutan, urbanisasi yang tidak terencana, manajemen pembuangan limbah yang buruk, mengabaikan peringatan dari data sistem hidrologi, dan kurangnya upaya pengendalian banjir (Etuonovbe, 2011).

Posisi wilayah terhadap sungai juga menjadi faktor pemicu terjadinya banjir. Salah satunya terdapat di Kampung Naga Tasikmalaya, dimana Kampung Naga bagian barat lebih tinggi jika dibandingkan dengan Kampung Naga bagian timur, dan Sungai Ciwulan berbatasan secara langsung dengan wilayah timur (Dewi \& Istiadi, 2016). Terdapat sekitar 600 sungai besar di Indonesia dengan kondisi buruk yang dapat menjadi pemicu terjadinya banjir (Sholihah et al., 2020)

Langkah paling penting untuk melakukan manajemen banjir yaitu memilih upaya yang efektif dan cocok seperti upaya langsung (pengurangan banjir, pengendalian banjir, dan penanggulangan banjir) yang fokus kepada bahaya dan kerentanan, dan upaya tidak langsung yang fokus kepada resiliensi. Sangat penting untuk memahami terlebih dahulu manfaat dari upaya yang akan dilakukan untuk mendesain pendekatan yang efisien (Bruijn et al., 2007)

Kota Langsa yang terletak di Provinsi Aceh juga menjadi daerah yang seringkali mengalami banjir. Dengan menganalisis tingkat risiko, kerentanan, dan bahaya dari bencana banjir, maka upaya mitigasi yang dapat dilakukan yaitu mitigasi struktural meliputi pembangunan tanggul, jaringan drainase, drop structure, serta mitigasi non-struktural seperti simulasi maupun pelatihan dan juga diperlukan evaluasi terhadap kebijakan pengurangan risiko dampak bencana banjir di Kota Langsa (Ningrum \& Ginting, 2020).

Pada tahun 2017 banjir terjadi sebanyak delapan kali dengan jumlah rumah terdampak yaitu 3.561 rumah di Kec. Bandar Dua, Kec. Meureudu, Kec. Jangka Buya, dan Kec. Ulim. Tahun 2018 banjir merusak dua rumah penduduk di Kec. Trienggadeng, tahun 2019 sebanyak enam ruang kelas terendam di SMA Negeri Kec. Bandar Baru, tahun 2020 sebanyak 60 rumah rusak akibat banjir, badan jalan di Kec. Bandar Baru dan saluran waduk sepanjang \pm 5 meter di Kec. Trienggadeng juga mengalami kerusakan. Pada awal tahun 2021 banjir terjadi kembali yang mengakibatkan sebanyak 22 rumah serta badan jalan sepanjang \pm 3 meter mengalami kerusakan 
di Kec. Bandar Dua, Kec. Ulim, dan Kec. Bandar Baru (BPBD Kabupaten Pidie Jaya, 2021).

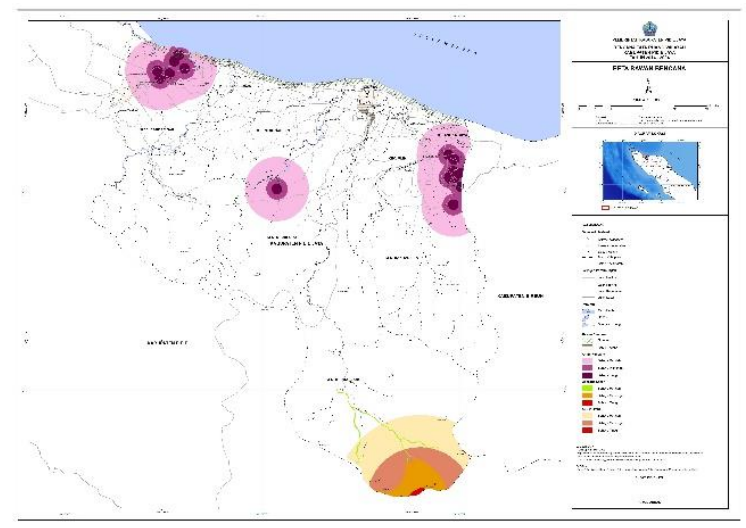

Gambar 1. Peta Rawan Bencana (RTRW Kabupaten Pidie Jaya, 2011)

Gambar 1 memperlihatkan peta rawan bencana yang terdapat di Kabupaten Pidie Jaya, Provinsi Aceh dimana terdapat beberapa wilayah yang rawan terhadap bencana banjir seperti di Kec. Bandar Dua, Kec. Meureudu, Kec. Meurah Dua, dan Kec. Bandar Baru. Wilayah yang rawan terhadap bencana banjir tersebut diketahui terletak didekat sungai.

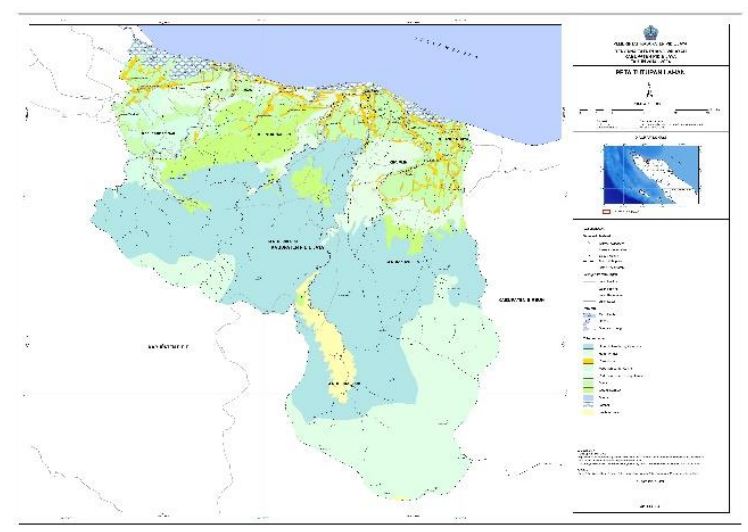

Gambar 2. Peta Tutupan Lahan (RTRW Kabupaten Pidie Jaya, 2011)

Pada Gambar 2 diperlihatkan bahwa kawasan permukiman digambarkan dengan warna kuning, sehingga dapat diketahui bahwa permukiman di Kabupaten Pidie Jaya lebih condong berada di area pesisir dan mengikuti aliran DAS yang terdapat di Kabupaten Pidie Jaya. Hal ini dikarenakan banyak masyarakat di Kabupaten Pidie Jaya yang bermatapencaharian sebagai nelayan dan petani (Handipa, 2021).
Hasil wawancara yang telah dilakukan dengan Plt. Kepala Pelaksana BPBD Kabupaten Pidie Jaya, diketahui bahwa upaya mitigasi banjir yang telah dilakukan untuk menanggulangi bencana banjir yaitu koordinasi dengan lintas sektor terkait (PUPR, Bappeda, Forum Pengurangan Risiko Bencana/FPRB, TNI-Polri, akademisi), melakukan identifikasi kawasan rawan bencana, melakukan sosialisasi dan memberikan edukasi tentang penanggulangan bencana, serta memperkuat struktural di kawasan tebing Krueng Meureudu, Krueng Putu, dan Krueng Jeulanga (Handipa, 2021).

Walaupun upaya mitigasi telah dilakukan, Kabupaten Pidie Jaya masih menghadapi masalah banjir sebagaimana yang terjadi pada awal tahun 2021. Informasi yang diperoleh dari Kepala Bappeda Kabupaten Pidie Jaya diketahui upaya mitigasi belum terlaksana secara maksimal namun pemerintah tetap berupaya melakukan segala upaya agar tujuan mitigasi dapat terwujud secara maksimal yaitu semakin berkurangnya wilayah terdampak banjir hingga tidak ditemukan lagi banjir yang mengganggu kehidupan masyarakat (Saiful, 2021).

Upaya mitigasi tidak akan dapat terlaksana secara maksimal apabila kondisi lingkungan masih menjadi faktor pemicu terjadinya banjir. Kepala Bidang Tata Lingkungan dan Penataan PPLH Dinas Lingkungan Hidup Kabupaten Pidie Jaya mengungkapkan masih ditemukan adanya praktek pembukaan lahan sembarangan. Pemerintah telah berusaha untuk menangani kasus tersebut, namun kurangnya pengawas lingkungan yang ahli di bidangnya menyebabkan tindakan penanggulangan penebangan ilegal tidak dapat dilakukan secara maksimal. Dinas Lingkungan Hidup hingga saat ini masih terus berupaya untuk memberitahu pengusaha untuk tidak melakukan pembukaan lahan sembarangan (Khariadi, 2021). Upaya mitigasi banjir juga didukung dengan peran Dinas Pekerjaan Umum yang mendukung upaya normalisasi sungai dan pembangunan tanggu (Fajri, 2021).

Berdasarkan hasil wawancara dapat diketahui bahwa, upaya mitigasi banjir sudah mulai dilakukan secara bertahap oleh Pemerintah Kabupaten Pidie Jaya, namun upaya mitigasi tersebut masih belum mencapai hasil yang maksimal. Pada awal tahun 2021 masih ditemukan beberapa wilayah yang terdampak 
banjir. Hal ini disebabkan upaya mitigasi yang dilakukan masih dihadapkan dengan berbagai kendala teknis. Salah satu cara untuk meminimalisir risiko terjadinya banjir yaitu memprediksi waktu potensial terjadinya banjir dan untuk menyusun rencana mitigasi yang tepat dan akurat dibutuhkan penilaian risiko. Penelitian yang dilakukan di Sungai Penuh, dari beberapa alternatif upaya mitigasi banjir, yang menjadi prioritas yaitu normalisasi muara sungai, memperbaiki koordinasi antar instansi yang terkait dengan mitigasi banjir, membangun sistem peringatan dini, dan melakukan sosialisasi dan pelatihan kepada masyarakat (Raflus et al., 2018).

Pengurangan risiko terjadinya banjir adalah salah satu metode praktis dalam mengurangi kerusakan. Hampir tidak mungkin semua wilayah dapat terhindar dari banjir, namun kerusakan yang ditimbulkan dapat dikurangi dengan rencana mitigasi. Rencana mitigasi banjir di Iran dibuat dengan membandingkan biaya yang dikeluarkan untuk membangun dan keuntungan dari upaya pengurangan risiko yang diperoleh. Hasil penelitian menunjukkan bendungan penahan dan pengalihan banjir merupakan upaya mitigasi yang terbaik (Heidari, 2009).

Terdapat beberapa rekomendasi dalam pengendalian banjir di Nigeria yaitu memperbaiki dan membangun sistem drainase yang baru, pembangunan saluran pengalihan banjir, pemerintah dan NGO seharusnya membuat berbagai program yang menginformasikan bahaya banjir kepada masyarakat, penyediaan fasilitas kesehatan yang adekuat, penyediaan pendanaan yang memadai oleh pemerintah untuk manajemen bencana, pemantauan secara berkala terhadap zona bencana, menggalakkan kegiatan penanaman pohon, pemerintah harus menghancurkan semua bangunan di sepanjang saluran air, dan membuat peraturan terkait pembuangan limbah (Adetunji \& Oyeleye, 2013).

Berdasarkan rekomendasi dari hasil penelitian terdahulu, maka upaya mitigasi yang sesuai dan dapat dilakukan oleh Pemerintah Kabupaten Pidie Jaya adalah dengan dibuatnya rencana kontinjensi dan dokumen kajian risiko bencana. Rencana kontinjensi dan dokumen kajian risiko bencana tersebut sangat penting dimiliki oleh setiap kabupaten/kota yang memiliki potensi bencana. Dokumen tersebut berfungsi sebagai acuan dalam melakukan mitigasi, penanggulangan saat pra, tanggap darurat, dan pasca bencana, serta dalam kegiatan pembangunan dapat memperhatikan risiko bencana yang ada dilokasi tersebut sehingga diharapkan penataan ruang di Kabupaten Pidie Jaya juga dapat lebih tertata dan terhindar dari risiko bencana yang besar. Pengadaan early warning system untuk bencana banjir sebagai salah satu upaya mitigasi juga diperlukan. Adanya early warning system ditujukan untuk masyarakat yang tinggal di wilayah rawan banjir sehingga mereka dapat mengetahui prakiraan waktu kapan banjir akan tiba di tempat tinggal mereka. Hal ini diharapkan agar masyarakat dapat bersiap dan mengamankan harta benda mereka dari banjir serta mengurangi risiko akibat banjir tersebut. Selain itu, perlu dilakukan penguatan hukum dan penindakan terhadap pelaku pembalakan liar yang terjadi di hulu DAS di Kabupaten Pidie Jaya yang merupakan salah satu penyebab terjadinya banjir.

\section{KESIMPULAN}

Pemerintah Kabupaten Pidie Jaya telah melakukan berbagai upaya mitigasi seperti, melakukan koordinasi lintas sektor, melakukan identifikasi kawasan rawan bencana, melakukan sosialisasi dan memberikan edukasi tentang penanggulangan bencana, serta memperkuat struktural di kawasan tebing Krueng Meureudu, Krueng Putu, dan Krueng Jeulanga. Namun, upaya tersebut tidak berjalan maksimal karena salah satu faktor penyebab banjir masih ada. Upaya mitigasi lainnya yang dapat dilakukan oleh Pemerintah Kabupaten Pidie Jaya adalah perlu dilakukan pembuatan rencana kontinjensi dan dokumen kawasan rawan bencana, perlu diadakannya early warning system untuk bencana banjir, serta penguatan hukum bagi pelaku illegal logging di kawasan hulu sungai yang menjadi salah satu faktor penyebab banjir.

\section{UCAPAN TERIMA KASIH}

Peneliti berterimakasih kepada instansi terkait yaitu BPBD, Dinas Lingkungan Hidup, Bappeda, dan Dinas Pekerjaan Umum Kabupaten Pidie Jaya, Provinsi Aceh yang telah 
memberikan data dan informasi pada penelitian ini.

\section{DAFTAR PUSTAKA}

Adetunji, M., \& Oyeleye, O. (2013). Evaluation of the Causes and Effects of Flood in Apete, Ido Local. 3(7), 19-27.

Afrian, R. (2020). Kajian Mitigasi Terhadap Penyebab Bencana Banjir di Desa Sidodadi Kota Langsa. Jurnal Georafflesia : Artikel Ilmiah Pendidikan Geografi, 5(2), 165-169. https://journals.unihaz.ac.id/index.php/georaf flesia/article/view/1660

Agbola, B. S., Ajayi, O., Taiwo, O. J., \& Wahab, B. W. (2012). The August 2011 flood in Ibadan, Nigeria: Anthropogenic causes and consequences. International Journal of Disaster Risk Science, 3(4), 207-217. https://doi.org/10.1007/s13753-012-0021-3

Badan Penanggulangan Bencana Aceh. (2016). Kajian Risiko Bencana Aceh 2016-2020.

Bariweni, P. A., Tawari, C. C., \& Abowei, J. F. N. (2012). Some Environmental Effects of Flooding in the Niger Delta Region of Nigeria. International Journal of Fisheries and Aquatic Sciences, 1(1), 35-46. http://maxwellsci.com/print/ijfas/v1-3546.pdf

Becker, P. (2018). Dependence, trust, and influence of external actors on municipal urban flood risk mitigation: The case of Lomma Municipality, Sweden. International Journal of Disaster Risk Reduction, 31(September), 1004-1012. https://doi.org/10.1016/j.ijdrr.2018.09.005

BPBD Kabupaten Pidie Jaya. (2021). Data Bencana Banjir di Kab. Pidie Jaya.

Bruijn, K. D., Green, C., Johnson, C., \& McFadden, L. (2007). Evolving concepts in flood risk management: Searching for a common language. In Flood Risk Management in Europe. Berlin/Heidelberg: Springer.

Dewi, I. K., \& Istiadi, Y. (2016). Mitigasi
Bencana pada Masyarakat Tradisional dalam Menghadapi Perubahan Iklim di Kampung Naga Kecamatan Salawu Kabupaten Tasikmalaya (Disaster Mitigation on Traditional Community Against Climate Change in Kampong Naga Subdistrict Salawu Tasikmalaya). Jurnal Manusia Dan Lingkungan, 23(1), 129. https://doi.org/10.22146/jml.18782

Dinas Lingkungan Hidup Kabupaten Pidie Jaya. (2021). Peran Dinas Lingkungan Hidup dalam Pengurangan Risiko Bencana di Kabupaten Pidie Jaya Guna Mendukung Keamanan Nasional.

Doocy, S., Daniels, A., Packer, C., Dick, A., \& Kirsch, T. D. (2013). The Human Impact of Earthquakes: A Historical Review of Events 1980-2009 and Systematic Literature Review. PLoS Currents, APR 2013, 1-27. https://doi.org/10.1371/currents.dis.67bd14fe 457f1 db0b5433a8ee20fb833

Erena, S. H., \& Worku, H. (2018). Flood risk analysis: causes and landscape based mitigation strategies in Dire Dawa city, Ethiopia. Geoenvironmental Disasters, 5(1). https://doi.org/10.1186/s40677-018-0110-8

Etuonovbe, A. K. (2011). The Devastating Effect of Flooding in Nigeria. Hydrography and the Environment Innocent Chirisa, Zimbabwe Inclusive Cities and Housing: Analysis of stewardship instruments in Epworth, Zimbabwe FIG Working Week. Bridging the Gap between Cultures Marrakech.

Fajri. (2021). Kuliah Kerja Dalam Negeri UNHAN RI: Sinergitas Pentahelix dalam Penanggulangan Bencana pada Masa Pandemi COVID-19 di Kabupaten Pidie Jaya Provinsi Aceh untuk Mendukung Keamanan Nasional. (Hasil Wawancara: 25 Maret 2021).

Handipa, O. (2021). Kuliah Kerja Dalam Negeri UNHAN RI: Sinergitas Pentahelix dalam Penanggulangan Bencana pada Masa Pandemi COVID-19 di Kabupaten Pidie Jaya Provinsi Aceh untuk Mendukung Keamanan Nasional. (Hasil Wawancara: 23 
Maret 2021).

Heidari, A. (2009). Structural master plan of flood mitigation measures. Natural Hazards and Earth System Science, 9(1), 61-75. https://doi.org/10.5194/nhess-9-61-2009

Ismail, N., Bakhtiar, B., Yanis, M., Darisma, D., \& Abdullah, F. (2020). Mitigasi dan Adaptasi Struktural Bahaya Banjir Berdasarkan Kearifan lokal Masyarakat Aceh Singkil. Jurnal Antropologi: Isu-Isu Sosial Budaya, 22(2), 276. https://doi.org/10.25077/jantro.v22.n2.p276285.2020

Khariadi, S. (2021). Kuliah Kerja Dalam Negeri UNHAN RI: Sinergitas Pentahelix dalam Penanggulangan Bencana pada Masa Pandemi COVID-19 di Kabupaten Pidie Jaya Provinsi Aceh untuk Mendukung Keamanan Nasional. (Hasil Wawancara: 25 Maret 2021).

Ningrum, S., \& Ginting, K. G. (2020). Strategi penanganan banjir berbasis mitigasi bencana pada kawasan rawan bencana banjir di Daerah Aliran Sungai Seulalah Kota Langsa. Geography Science Education Journal, 1(1), 6-13.

Nquot, I., \& Kulatunga, U. (2014). Flood Mitigation Measures in the United Kingdom. Procedia Economics and Finance, 18(September), 81-87. https://doi.org/10.1016/s22125671(14)00916-2

Prawira, M. P., \& Pamungkas, A. (2014). Mitigasi Kawasan Rawan Banjir Rob di Kawasan Pantai Utara Surabaya. Jurnal Teknik Pomits, 3(2), C-160-C-165.

Raflus, R. U., Iskarni, P., \& Legaya, N. (2018). Mitigation Policy of Flood Disaster in Sungai Penuh Town Province of Jambi, Indonesia. Sumatra Journal of Disaster, Geography and Geography Education, 2(1), 8. https://doi.org/10.24036/sjdgge.v2i1.135
Saiful. (2021). Kuliah Kerja Dalam Negeri UNHAN RI: Sinergitas Pentahelix dalam Penanggulangan Bencana pada Masa Pandemi COVID-19 di Kabupaten Pidie Jaya Provinsi Aceh untuk Mendukung Keamanan Nasional. (Hasil Wawancara: 24 Maret 2021).

Sholihah, Q., Kuncoro, W., Wahyuni, S., Puni Suwandi, S., \& Dwi Feditasari, E. (2020). The analysis of the causes of flood disasters and their impacts in the perspective of environmental law. IOP Conference Series: Earth and Environmental Science, 437(1). https://doi.org/10.1088/17551315/437/1/012056

Tariq, M. A. U. R., Farooq, R., \& van de Giesen, N. (2020). A critical review of flood risk management and the selection of suitable measures. Applied Sciences (Switzerland), 10(23), 1-18.

https://doi.org/10.3390/app10238752

Wibowo, Y. A., Ronggowulan, L., Arif, D. A., Afrizal, R., Anwar, Y., \& Fathonah, A. (2019). Perencanaan Mitigasi Bencana Banjir Non-Struktural Di Daerah Aliran Sungai Comal Hilir, Jawa Tengah. JPIG (Jurnal Pendidikan Dan Ilmu Geografi), 4(2), 87-100.

https://doi.org/10.21067/jpig.v4i2.3632

Youssef, A. M., Sefry, S. A., Pradhan, B., \& Alfadail, E. A. (2016). Analysis on causes of flash flood in Jeddah city (Kingdom of Saudi Arabia) of 2009 and 2011 using multi-sensor remote sensing data and GIS. Geomatics, Natural Hazards and Risk, 7(3), 1018-1042. https://doi.org/10.1080/19475705.2015.1012 750 